Article

\title{
Developing a Real-time Monitoring Traceability System for Cold Chain of Tricholoma matsutake
}

\author{
Xinwu Li ${ }^{1}$, Lin Yang ${ }^{2}$, Yanqing Duan ${ }^{3}$, Zhigang $\mathrm{Wu}^{4}$ and Xiaoshuan Zhang ${ }^{1, *}$ \\ 1 Beijing Laboratory of Food Quality and Safety, College of Engineering, China Agricultural University, \\ Beijing 100083, China; xinwuli@cau.edu.cn \\ 2 College of Food Science, Tibet Agricultural and Animal Husbandry College, Linzhi 860000, China; \\ yanglin8989239@163.com \\ 3 Business and Information Systems Research Centre (BISC), Business School, University of Bedforshire, \\ Luton LU1 3JU, UK; yanqing.duan@beds.ac.uk \\ 4 College of Continuing Studies, China Agricultural University, Beijing 100083, China; wuzhigang@cau.edu.cn \\ * Correspondence: zhxshuan@cau.edu.cn; Tel.: +86-010-62737663
}

Received: 28 February 2019; Accepted: 8 April 2019; Published: 11 April 2019

check for updates

\begin{abstract}
Tricholoma matsutake (T. matsutake) is a special type of fungus known as "the king of bacteria", and has the very high economic value. However, it is also very difficult to transport due to its corruptibility. Therefore, tracing and tracking the quality and safety of T. matsutake in the cold chain is very important and necessary. Based on changes in the cold chain environmental parameters determine the safety of T. matsutake is a viable option. This paper developed and tested a real-time monitoring traceability system (RM-TM) using emerging Internet of Things (IoT) technologies for monitoring the cold chain logistics environmental parameters of T. matsutake. Finally, system testing and evaluation have shown that RM-TM can track and monitor temperature, humidity, oxygen and carbon dioxide fluctuations in the cold chain in real-time. In addition, the collected data can be used to increase the transparency of cold chain logistics and to more effectively control quality, safety, and traceability. In general, the system evaluation results show that it is reliable and meets the requirements of users.
\end{abstract}

Keywords: T. matsutake; logistics environment parameters; safety; real-time; wireless monitoring; traceability system

\section{Introduction}

Tricholoma matsutake is a rare and edible wild fungus [1,2]. As a popular delicacy food, T. matsutake has high economic value as an important source of income for the rural area in southwestern China [3,4]. Meanwhile, T. matsutake is the most valuable species throughout the world, exhibiting a characteristic and delicate flavor as well as several biological activities [5]. Nowadays, T. matsutake's quality and safety have received worldwide attention. Fresh T. matsutake has the characteristics of high water content, soft tissue and no surface protection structure. The respiration and transpiration of T. matsutake were severe. Therefore, temperature, humidity, and gas composition is an important factor affecting the quality of T. matsutake in the storage and transportation [6]. For T. matsutake products the control of temperature, humidity and gas composition is essential.

In recent years, the Internet of Things (IoT) has become an important research topic [7-11], and the emerging IoT technologies are gradually ripening. After nearly a decade of development, the definition of the IoT has become more extensive, and the application of IoT involves more fields that include supply chain management, health care, utilities, transportation and other field. In general, the IoT includes two important features: one is to collect data and connect itself to the cloud's perceived 
entities, and the other is to host cloud services that use data collected by sensing devices [12,13]. IoT has been used widely. For example, a number of projects use IoT and wireless sensor network technologies to achieve the control of temperature of cold chain for agricultural products [14-17]; for reducing the loss of fresh agricultural products and ensuring the food safety IoT has been widely used in the process of cold chain logistics, such as a real-time monitoring wireless sensor network system for agricultural products [18], mango [19], grapes [20], apple [21], and for frozen and chilled aquatic products [22].

Compared to SD (Secure Digital Memory Card) card-based temperature recorder [23] the wireless transmission system has many advantages including better flexibility, higher mobility and fast deployment in special occasions [24,25]. The monitoring system mostly uses the wireless transmission method, such as a cool box temperature monitoring in cold chain logistics was presented, which used wireless sensor module (WSM) and network [26], and a web-based platform for collecting temperature conditions data throughout the chilled and frozen food supply chain [27].

Generally, perishable food produces a large amount of data from the production process to the circulation. And these data can be obtained through multi-source sensor monitoring, GPS, mobile, internet, and other channels. Then, by analyzing the data and modeling, it is possible to predict the shelf life of fresh produce. The literature also presents several contributions on the control of food safety and shelf life (SL) of products. In order to guarantee and control food safety and shelf life (SL) of products, a supply chain monitoring system was developed based on a smart logistic unit (SLU) dedicated to perishable food products [28]. A smart logistic unit (SLU) equipped with a GPS module and a $3 \mathrm{G}$ connection module was used to real time position the truck and remote quality supervision [29]. Based on the previous studies, this paper aims to develop a real-time monitoring traceability system (RM-TM) using emerging IoT technologies for monitoring the cold chain logistics environmental parameters of T. matsutake. Section 2 describes the RM-TM system analysis. Section 3 shows the system design of the RM-TM, Section 4 shows the implementation and evaluation of RM-TM and, finally, Section 5 concludes the paper with a short discussion on the proposed the future work.

\section{RM-TM System Analysis}

\subsection{The Survey Design and Analysis}

The main production area of T. matsutake is in the southwestern provinces of China, such as Yunnan, Sichuan, and Tibet, with a total output of over $90 \%$. At present, the T. matsutake supply chain mainly includes harvesting, grading, pretreatment, packaging, transportation, customs declaration, inspection and so on. For understanding the unique features of the T. matsutake supply chain for RM-TM design, this study conducted a survey on the T. matsutake processing enterprises in Tibet province.

The detailed production process of T. matsutake and RM-TM's requirements are obtained using the following methods.

- Field Observation was used to determine the workflow of the T. matsutake cold chain logistics. The researchers tracked a batch of T. matsutakes and recorded relevant information.

- Interview was used to obtain the user's requirements for RM-TM's functionality. With the assistance of local processing enterprises, we interviewed 21 people that including five managers and 16 workers. The interviews with workers are mainly the workflow and control standards in their own operating practices. Meanwhile, the interviews with the manager are mainly about the requirements for the RM-TM.

\subsection{Workflow of T. matsutake Cold Chain Logistics}

We have chosen Nyingchi prefecture as the location of the survey of T. matsutake supply chain. During the observation, we captured the workflow of T. matsutake production process. Figure 1 
describes the supply chain of T. matsutake, which represents Nyingchi's most common T. matsutake supply chain and explains the links that need to be monitored in the supply chain.
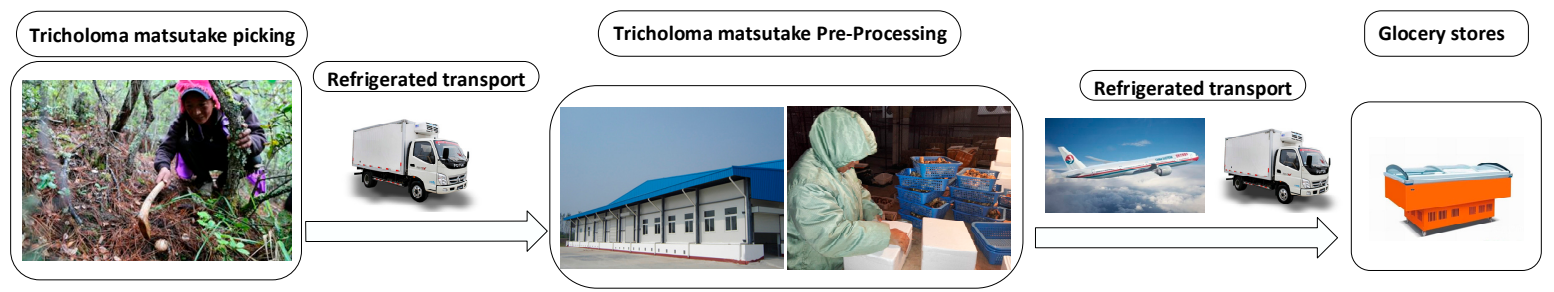

Figure 1. The supply chain of T. matsutake.

In this study, the monitoring system mainly monitors and tracks the cold chain environment of this chain. And the process consists of following steps:

Step 1: After picking the T. matsutake from the mountain, the picker sells it to the middleman. Then, the T. matsutakes are sent to processing plants by van or other vehicles with simple insulation facilities.

Step 2: Grading and packing processing of T. matsutake.

Step 3: Pre-cooling treatment of T. matsutake to preserve the freshness of T. matsutake.

Step 4: Transporting the T. matsutake to grocery stores and supermarkets for sale.

Step 5: Wholesalers and retailers sell the T. matsutake in the market.

Table 1 is the workflow of T. matsutake's cold-chain logistics and lists the key profiles. For ensuring the quality and safety of the mushroom, the ideal storage and refrigerated transportation temperature of entire logistics chain should be maintained between $1-4{ }^{\circ} \mathrm{C}$.

Table 1. Workflow of T. matsutake's cold-chain logistics.

\begin{tabular}{|c|c|c|c|}
\hline Step & Operation & Description & Remark \\
\hline 2 & Transportation & Fresh T. matsutakes are transported to the processing plants & $\begin{array}{l}\text { Transported at the ambient } \\
\text { temperature }\end{array}$ \\
\hline 3 & Grading & $\begin{array}{l}\text { Fresh } T \text {. matsutakes are divided into several quality levels } \\
\text { according to the maturity and sizes }\end{array}$ & $\begin{array}{l}\text { Select the T. matsutakes with } \\
\text { good quality }\end{array}$ \\
\hline 4 & Package & Place the T. matsutakes in a foam box and seal the box with tape. & / \\
\hline 6 & Loading & Loading T. matsutakes to the refrigerated truck or airplane & / \\
\hline 7 & Transportation & $\begin{array}{l}\text { T. matsutakes are transported to the markets by refrigerated } \\
\text { transportation }\end{array}$ & $\begin{array}{l}\text { Transported at the temperature } \\
\text { ranges between } 1-4{ }^{\circ} \mathrm{C}\end{array}$ \\
\hline 8 & Sale & T. matsutakes are sold in the markets & $\begin{array}{l}\text { Ambient temperature ranges } \\
\text { between } 1-4{ }^{\circ} \mathrm{C}\end{array}$ \\
\hline
\end{tabular}

\subsection{Requirements Analysis of RM-TM}

The knowledge about the requirements of RM-TM was obtained from interviews and the work flow observations.

- For managers: (1) The RM-TM can display the information of temperature, humidity, oxygen, carbon dioxide, and geographic location parameters of the cold chain in real-time. Once the threshold value is exceeded, the alarm information can be displayed to the management personnel. (2) For meeting the actual requirements, the characteristics of the RM-TM should include high precision, wide measurement range and fast response time. (3) The communication performance of RM-TM c should be stable and have certain anti-interference ability. (4) The information collection device of the RM-TM should be low power, low cost, and can be deployed flexibly. (5) Managers can track the final production.

- For consumers: Consumers can query information about the origin of the T. matsutake, and the date and location of the harvest by using the website address to link to the system. Meanwhile, consumers can also query the history information of T. matsutake in cold chain logistics. 


\section{System Design of RM-TM}

\subsection{System Architecture Design}

Figure 2 shows the architecture of the RM-TM that consists of three layers that include data collection layer, data transmission layer, and data management layer.

1. The data collection layer is mainly responsible for the collection and transmission of information data. The information gathering node needs a multi-parameter information collection and fusion device, which is placed in the package of T. matsutakes to collect and send the storage micro-environment information data.

2. The data transmission layer is mainly responsible for transmitting data Base station (public mobile communication base station) serves as a hub for data transmission, receives the sensed data from the information gathering node and groups them for transmission to the data management layer for storage and processing.

3. The data management layer is mainly responsible for the implementation of real-time data acquisition, storage, display, and processing and other basic functions. It mainly includes data base, knowledge base, model base, application server, and so on. Moreover, it provides historical data query capabilities for cold chain information data, while providing easy-to-use operating and configuration interfaces for managers.

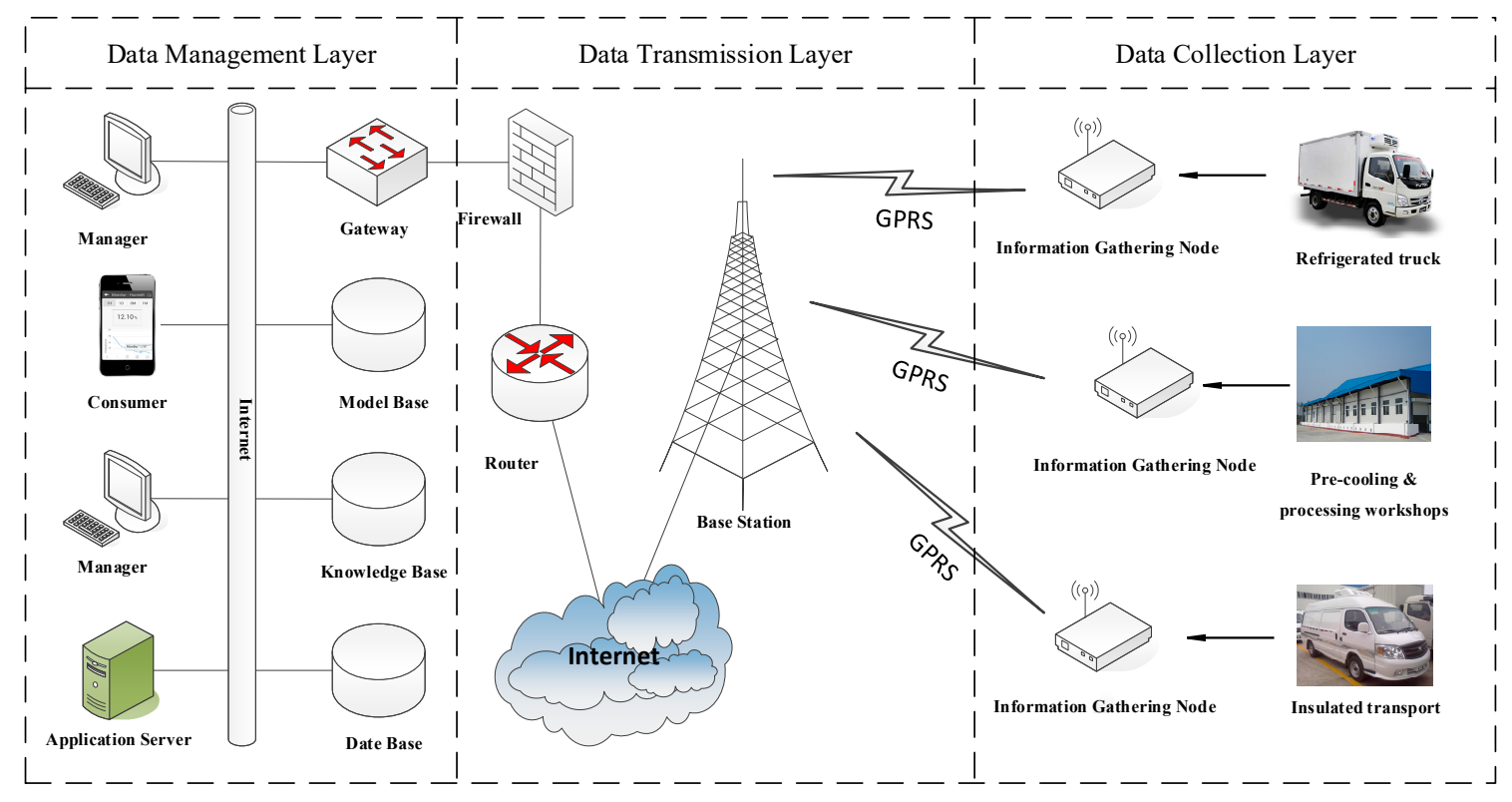

Figure 2. System architecture of RM-TM.

Table 2 is the instructions of components. And it provides the type, manufacturer, city and country of all components used in the RM-TM.

\subsection{Hardware Design of RM-TM}

A multi-parameter information acquisition and fusion device was designed and developed to solve the problem of the multi-parameters in the cold chain environment. The hardware architecture consists of four modules that include power supply module, sensing module, information processing module, and GPRS wireless communication module (see Figure 3). Power supply module supplies power to the entire device. Sensing module captures the environmental information and geographic parameters in the cold chain by using humidity sensor, temperature sensor, carbon dioxide sensor, 
oxygen sensor and GPS device. The processing module processes the data that received from sensing module, and sends the data to the monitoring center via GPRS wireless communication module.

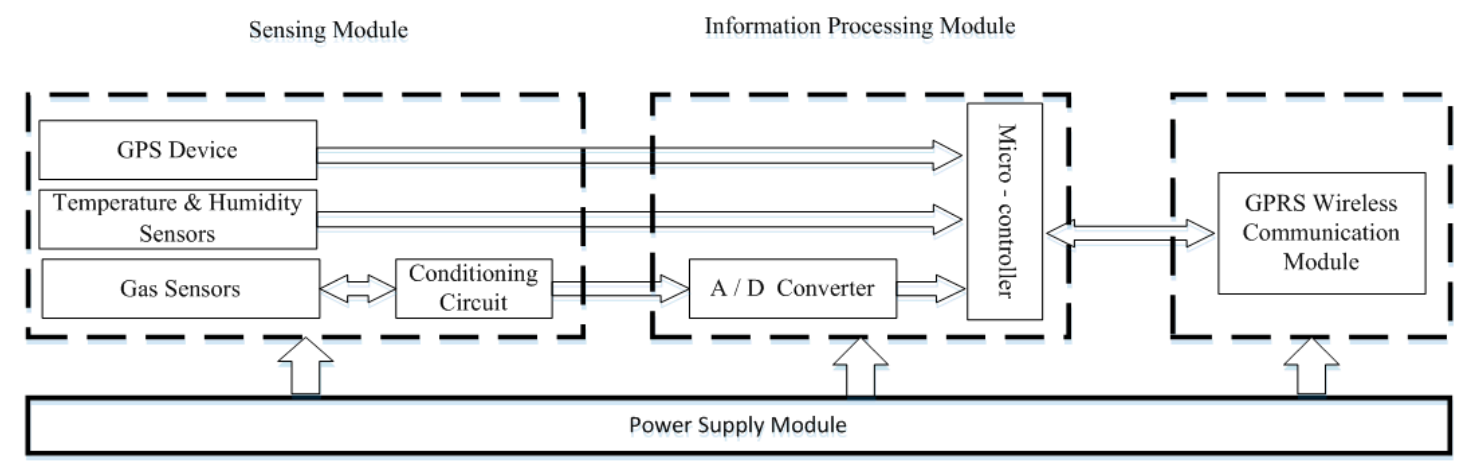

Figure 3. RM-TM system components and information flow.

Table 2. Instructions of components.

\begin{tabular}{|c|c|c|c|c|}
\hline \multicolumn{2}{|c|}{ Component } & Type & Manufacturer & $\begin{array}{c}\text { Place of } \\
\text { Production }\end{array}$ \\
\hline \multirow{2}{*}{$\begin{array}{c}\text { Information } \\
\text { Processing Module }\end{array}$} & MCU (Microcontroller Unit) & STC12C5A60S2 & STC MCU Limited & Beijing, China \\
\hline & PCB (Printed Circuit Board) & FR-4 & $\begin{array}{l}\text { Hangzhou Jiepei } \\
\text { Technology Co., Ltd. }\end{array}$ & Hangzhou, China \\
\hline \multirow{3}{*}{ Sensing Module } & $\begin{array}{l}\text { Humidity \& Temperature } \\
\text { sensor }\end{array}$ & AM2302 & $\begin{array}{l}\text { Aosong (Guangzhou) } \\
\text { Electronics Co., Ltd. }\end{array}$ & Guangzhou, China \\
\hline & $\mathrm{CO}_{2}$ sensor & $\mathrm{AJD} / \mathrm{L} / 4 \mathrm{CO}_{2}$ & \multirow{2}{*}{$\begin{array}{l}\text { Beijing Anjieda } \\
\text { Technology Co., Ltd. }\end{array}$} & \multirow[b]{2}{*}{ Beijing, China } \\
\hline & $\mathrm{O}_{2}$ sensor & AJD-4M-O 2 & & \\
\hline GPRS Module & $\begin{array}{l}\text { GPRS (General Packet Radio } \\
\text { Service) }\end{array}$ & KS97-GPRS & Kytence Electronic & Shanghai, China \\
\hline $\begin{array}{l}\text { Power Supply } \\
\text { Module }\end{array}$ & Power Supply & $9 v 30 a h$ & $\begin{array}{c}\text { Beijing Oulieng } \\
\text { Electronic Technology } \\
\text { Co., Ltd. }\end{array}$ & Beijing, China \\
\hline
\end{tabular}

Sensing module includes temperature sensor, humidity sensor, gas sensor, and GPS device. These sensors and component (include battery, GPS and GPRS module) are directly purchased from the electronics manufacturers. This study designs its own modules. Firstly, the circuit of multi-parameter information acquisition and fusion device is developed using Altium Designer16.0 (developed by Protel International Limited), and is shown in Figure 4. Then the corresponding PCB is developed. The main line program of the multi-parameter information acquisition and fusion device is shown in Figure 5. Finally, the project completed the manufacture of hardware by PCB designing, welding, programming, and other processes. 


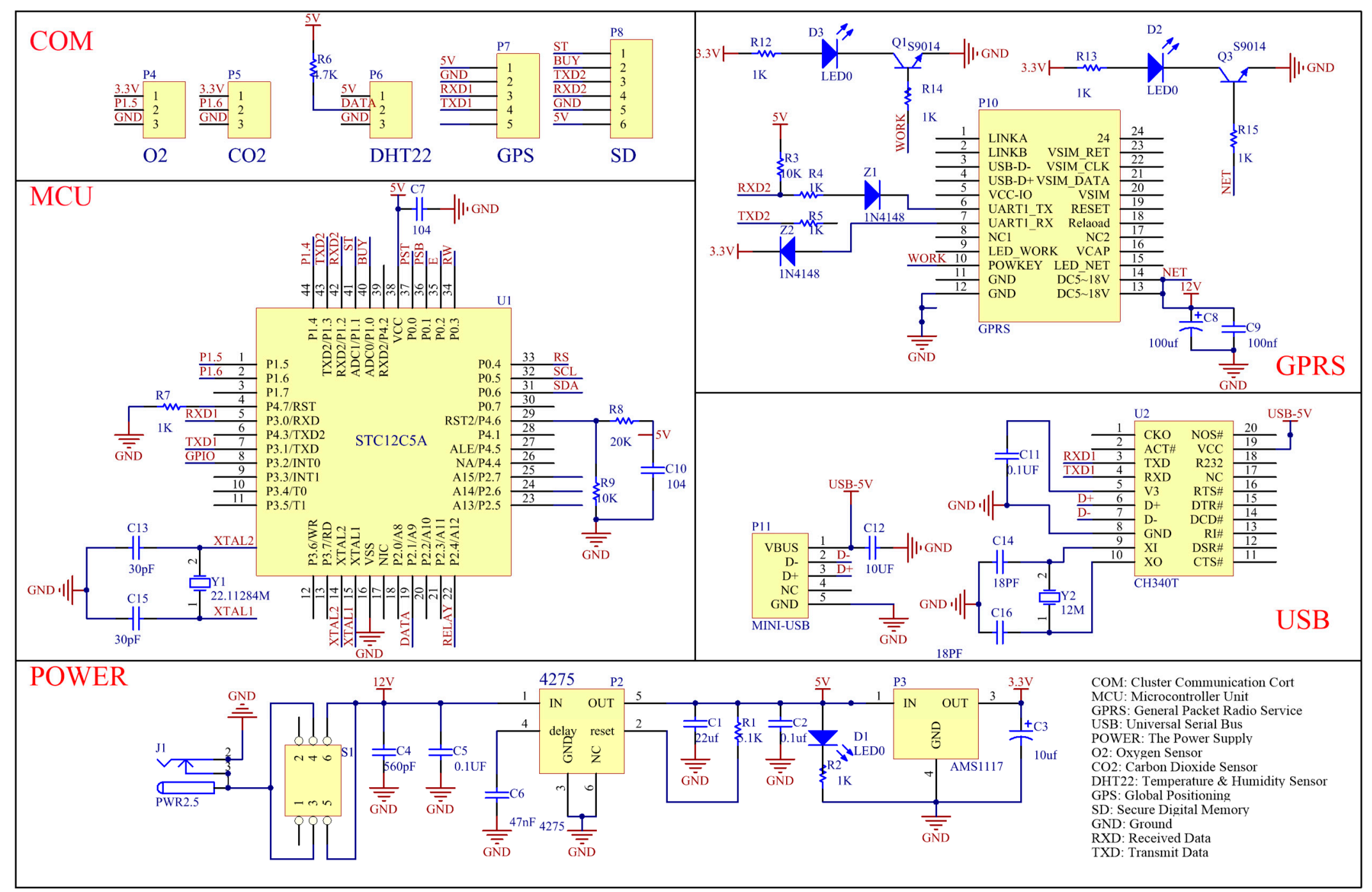

Figure 4. Circuit of the multi-parameter information acquisition and fusion device. 


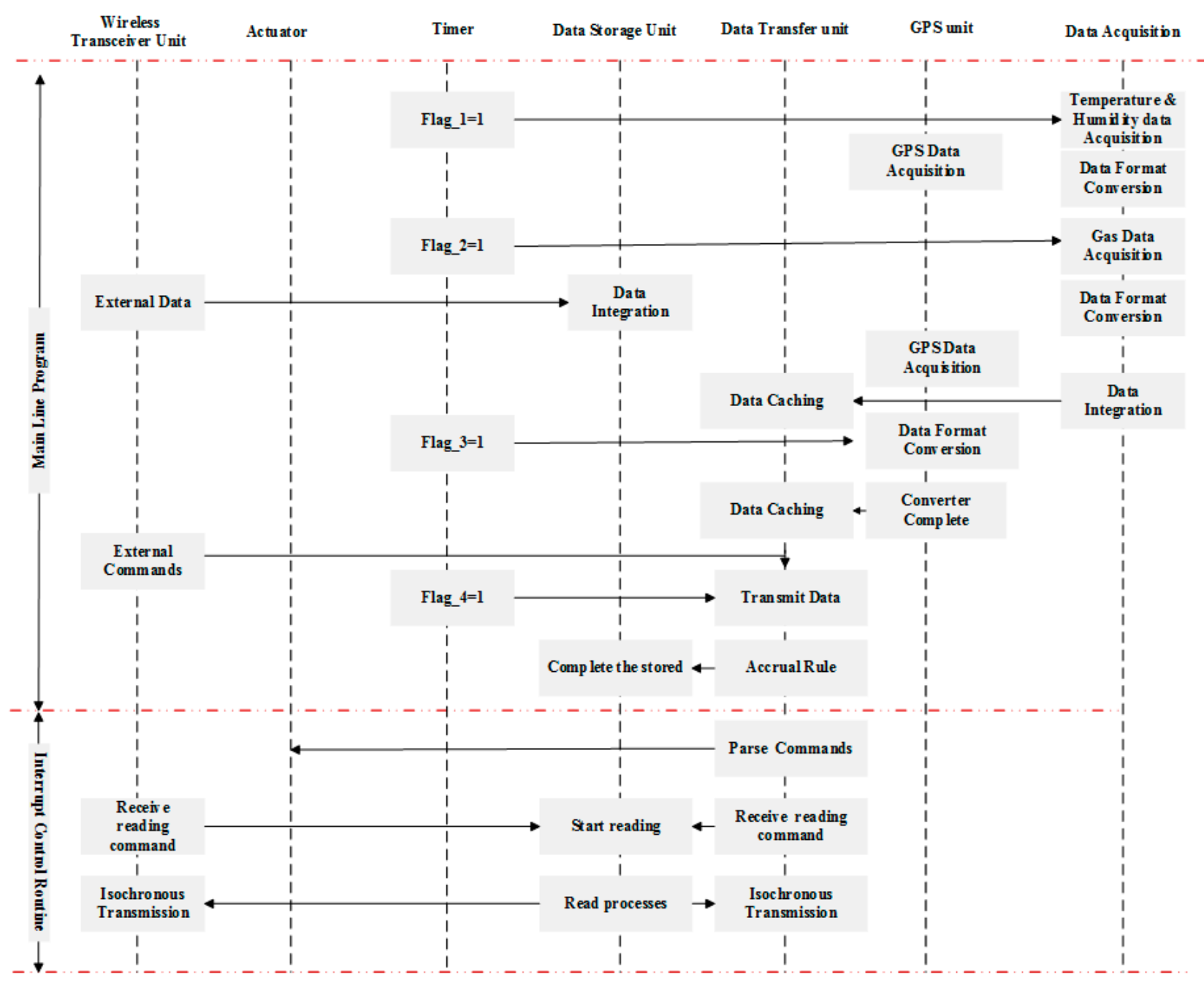

Figure 5. Main line program of the multi-parameter information acquisition and fusion Device. 


\subsection{Application Software Design of the RM-TM}

The software function is designed for meeting the different needs of managers and consumers.

- Functional Design for Managers. The software modules include the user and monitoring centers, and device, trigger, feedback, and exploration modules, as shown in Figure 6. In the user center, the user can set personal information and account password. In device module, it has temperature, humidity, and gas (oxygen and carbon dioxide) sensors. The monitoring center module includes data display, data query, data analysis and data storage. The trigger module includes alarm mode and threshold settings, and in the future, we will continue to realize the function of remote control matsutake storage and transportation environment via mobile phone. If users have any suggestions, they can use the feedback module to submit their feedback. In the exploration module, the user can search for other Internet of Things devices. The software workflow shown in Figure 7.

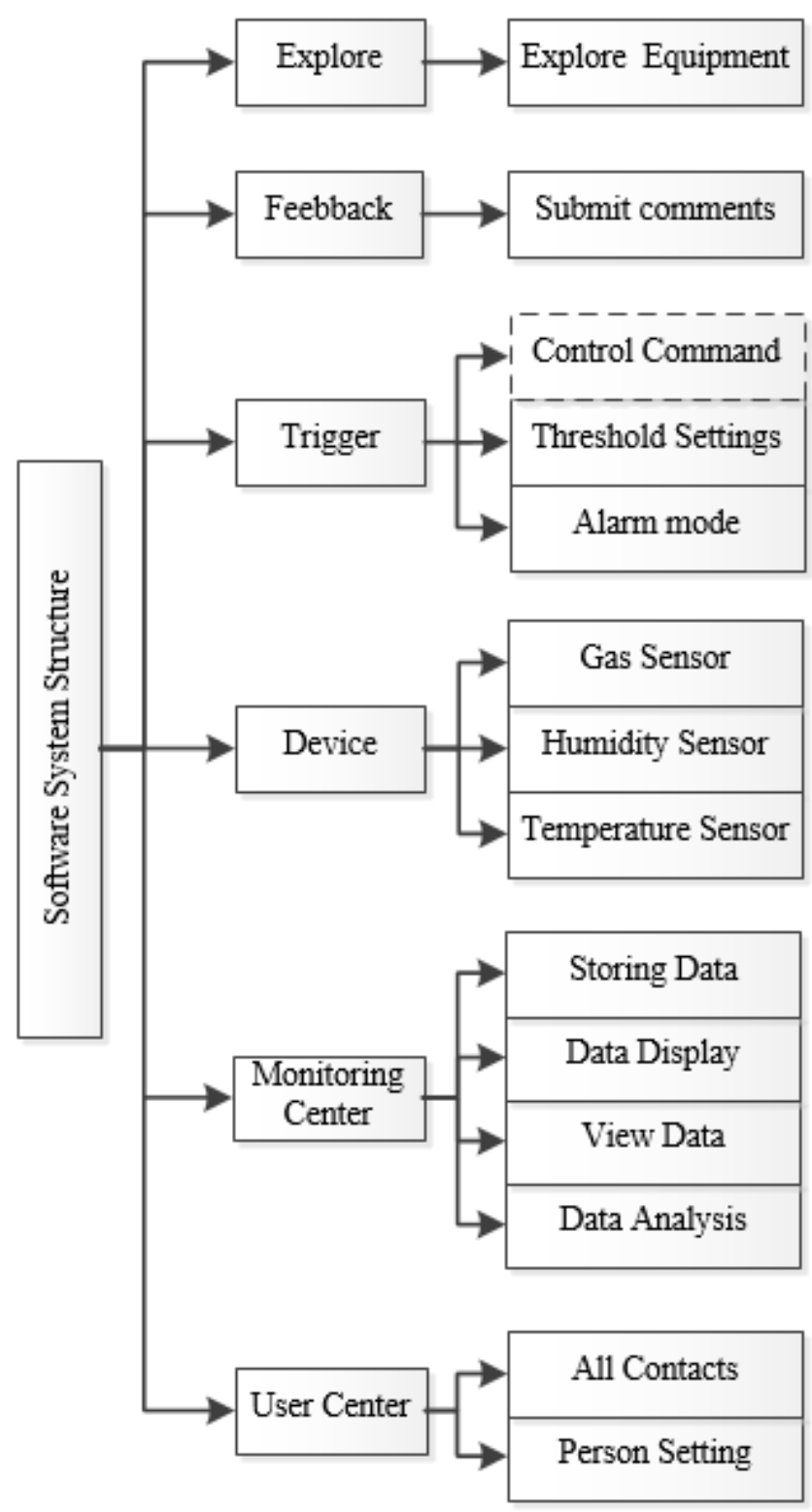

Figure 6. Functional design of software for managers. 
- Functional Design for Consumers. Considering consumers' growing interest in the maturation process and quality control of the matsutake, we plan to develop application software for consumers. The module design is shown in Figure 8. In the login and authentication module, the user can set personal information and account password. The monitoring center module includes data display, data query, data analysis, and accurate query. In the future, we plan to continue to add the product ordering module to facilitate the use of consumers (for other reasons, the design of the software for consumers has not yet been completed).

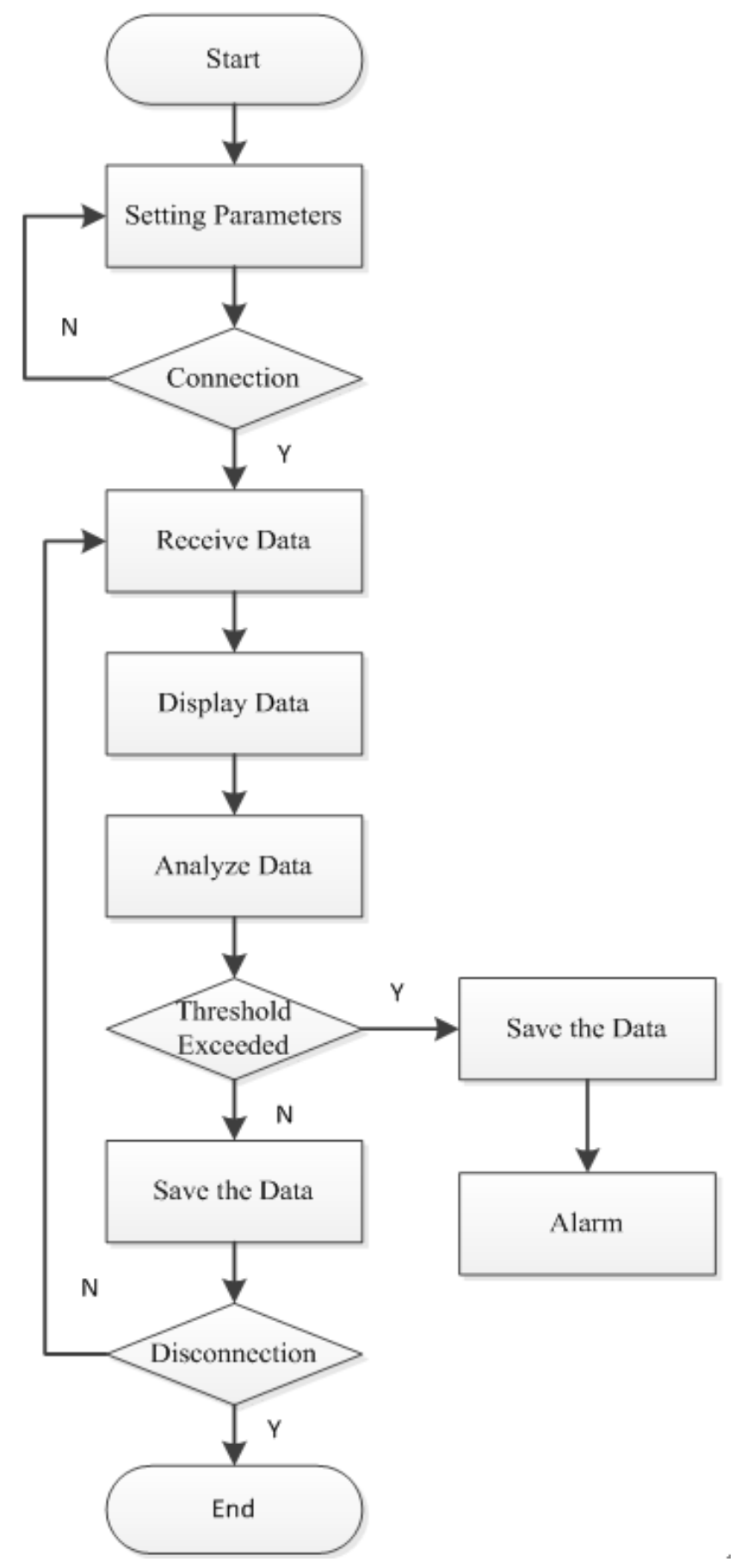

Figure 7. Software workflow. 


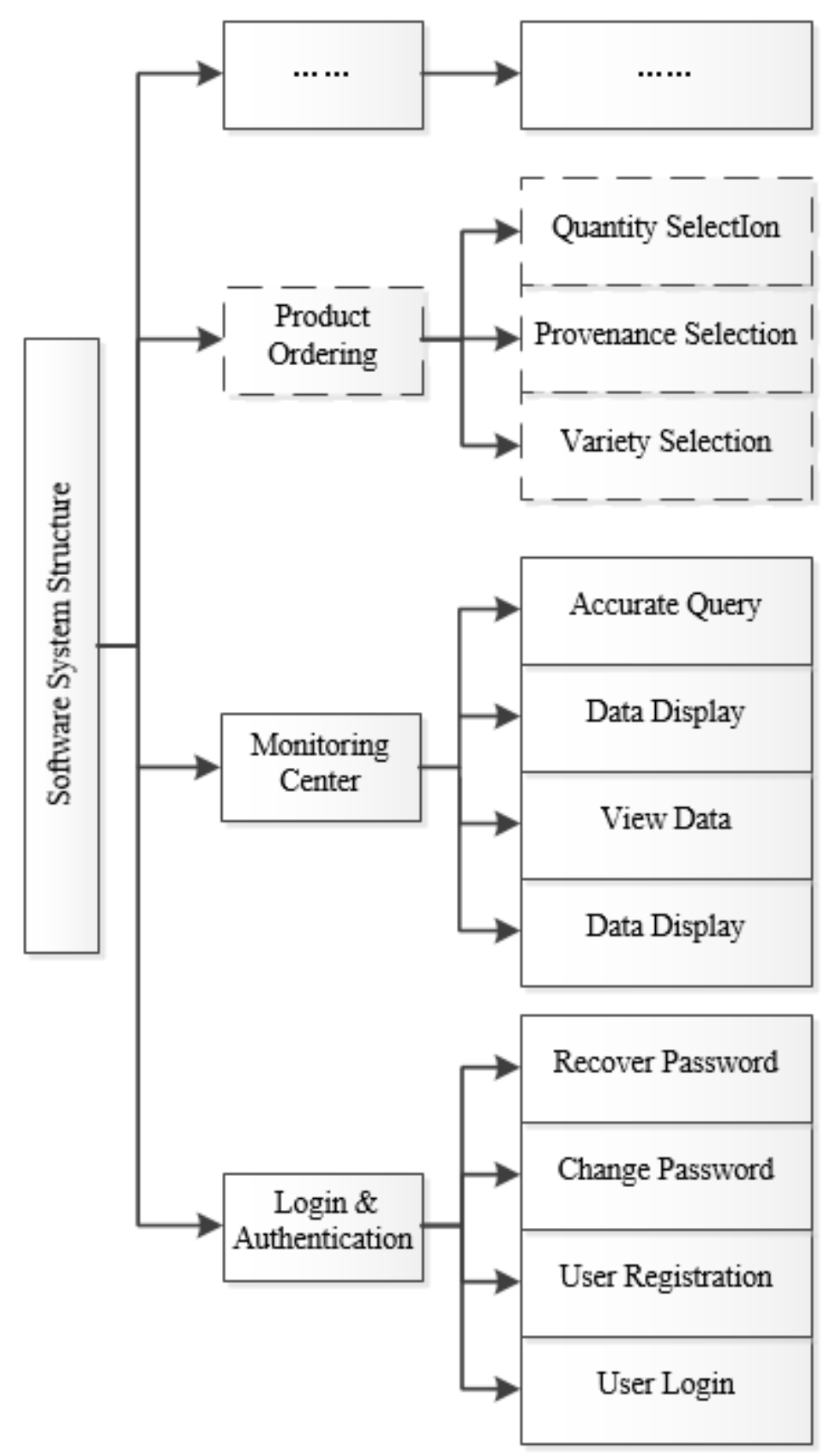

Figure 8. Functional design of software for consumers.

\section{Implementation and Evaluation of RM-TM}

\subsection{Hardware Implementation and Testing}

In this study, we have designed and developed a multi-parameter information acquisition and fusion device that consists of power supply module, information processing module, sensing module, and GPRS wireless communication module. Figure 9a shows the multi-parameter information acquisition and fusion device. Figure $9 \mathrm{~b}$ shows the internal structure of the information processing module. The GPRS module is embedded in the information processing module, which makes the device realize the functions of real-time wireless transmission and receiving data. The device captures the environmental information in the cold chain by using temperature, humidity, oxygen, and carbon dioxide sensors. The data collecting method from sensor is interval mode, and the time interval of the measuring environment is set according to the user's requirements. 


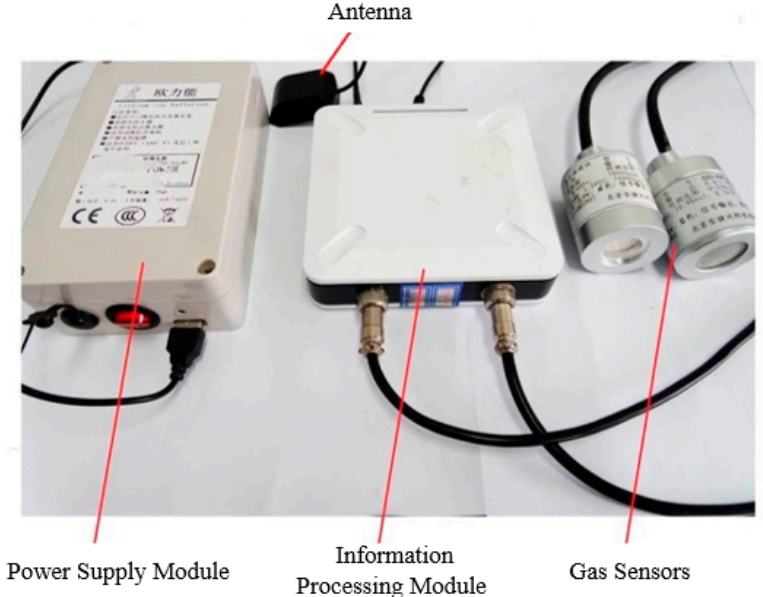

(a)

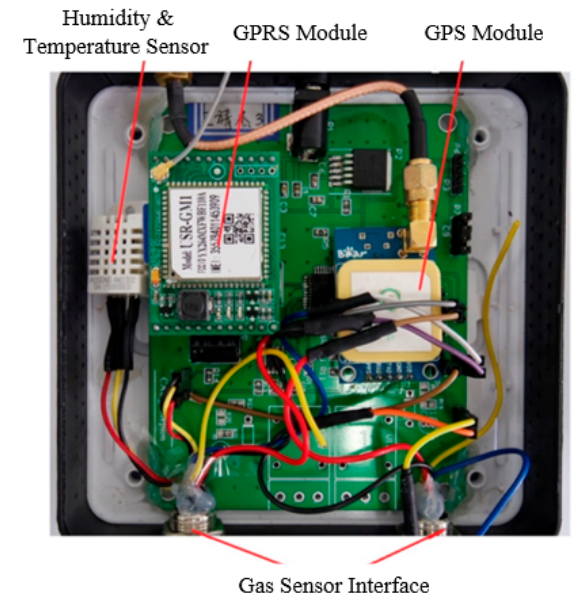

(b)

Figure 9. Photo image of hardware: (a) multi-parameter information acquisition and fusion device; and $(\mathbf{b})$ the information processing module.

The device has realized the function of real-time monitoring and recording of the temperature, humidity, oxygen, and carbon dioxide and geo-parameter information in the cold chain logistics. In addition the performance indicators of device are listed in Table 3.

Table 3. Performance indicators of the device.

\begin{tabular}{cccc}
\hline Indications & Resolution & Range & Tolerance Scope \\
\hline Temperature $\left({ }^{\circ} \mathrm{C}\right)$ & 0.1 & $-40-80$ & \pm 0.3 \\
Humidity $(\% \mathrm{RH})$ & 0.1 & $0-100$ & \pm 2 \\
$\mathrm{O}_{2}(\%$ vol $)$ & 0.1 & $0-30$ & \pm 2 \\
$\mathrm{CO}_{2}(\% \mathrm{vol})$ & 0.1 & $0-5$ & \pm 1 \\
\hline
\end{tabular}

\subsection{Device Power Consumption Test}

The main component power consumption of the multi-parameter information acquisition and fusion device is shown in Table 4. The power consumption of the device is mainly determined by the power consumption of the gas sensor and the GPRS wireless communication module. In comparison, the power consumption of the carbon dioxide sensor is relatively small, and the power consumption of the oxygen sensor and the GPRS wireless communication module are relatively large. Moreover, the higher the accuracy of the gas sensor, the greater the power consumption. Therefore, reducing the power consumption of the gas sensor and GPRS wireless communication module is the key to reducing the overall power consumption of the device. According to the analysis of system requirements, the best solution for reducing the power consumption of the multi-parameter information acquisition and fusion device is by extending the sleep time and reducing acquisition frequency of the device.

Table 4. The main component power consumption of the device.

\begin{tabular}{ccc}
\hline Component & Model Number & Power \\
\hline \multirow{2}{*}{ MCU } & STC12C5A60S2 & working state: $10-35 \mathrm{~mW}$ \\
\cline { 2 - 3 } & STC MCU Limited & sleep state: $6.5 \mathrm{~mW}$ \\
\hline Humidity \& temperature sensor & $\mathrm{AM} 2302$ & $1-30 \mathrm{uW}$ \\
$\mathrm{CO}_{2}$ sensor & $\mathrm{AJD} / \mathrm{L} / 4 \mathrm{CO}_{2}$ & $25 \mathrm{~mW}$ \\
$\mathrm{O}_{2}$ sensor & $\mathrm{AJD}-4 \mathrm{M}-\mathrm{O}_{2}$ & $200 \mathrm{~mW}$ \\
GPRS module & $\mathrm{KS} 97-\mathrm{GPRS}$ & $170-350 \mathrm{~mW}$ \\
\hline
\end{tabular}




\subsection{Software Implementation and Testing}

The application software developed in this research include mobile version and PC (Personal Computer) version, which allow users to have real-time monitoring of the environment of cold chain and query historical data of cold chain environment information. The software of RM-TM proposed in this research has been developed based on the TLINK Cloud Services Platform. As an extension of connection tool, TLINK Cloud Services Platform provides real-time connection of million sensing nodes. In addition, it supports open API interface for secondary treating and development of data. Meanwhile, it also enables standard protocol integration of internet of things, such as, SEP (Spanning Tree Protocol), MQTT (Message Queuing Telemetry Transport), etc.

The software homepage of mobile version is shown in Figure 10a, which consists of a user center, monitoring center, device, trigger, feedback and exploration modules. Among them, in the device module, the user can add options of sensing device according to their own needs. According to the capabilities of multi-parameter information acquisition and fusion device, we added humidity, temperature, oxygen, and carbon dioxide options, then set the data upload time interval, mapping function and, finally, implement the link between the multi-parameter information acquisition and fusion device and the TLINK cloud services platform by the TCP (Transmission Control Protocol) protocol.

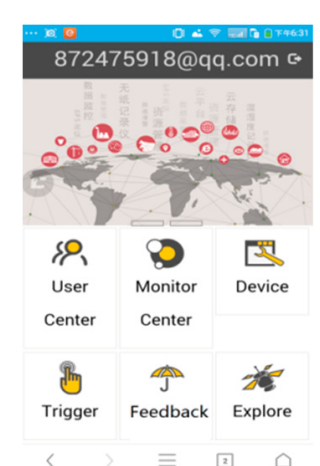

(a)

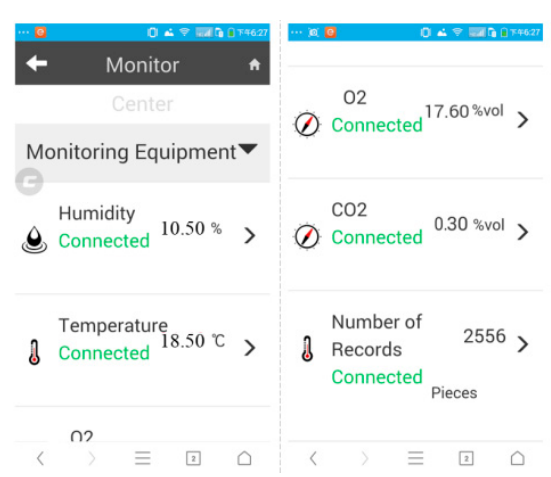

(b)

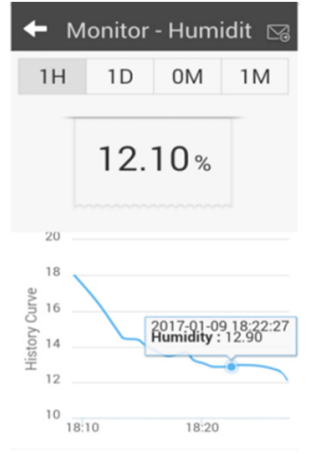

(c)

Figure 10. Screenshot of the software interface of mobile version:

(b) monitoring center screenshot; and (c) information processing module.

(a) software homepage;

A monitoring center screenshot of mobile version is shown in Figure 10b. When the sensor device is connected successfully, by clicking the monitoring center icon, the user can obtain the real-time temperature humidity, temperature, oxygen, and carbon dioxide data of cold chain environment. Meanwhile, the user can also query the historical data of the cold chain environment by clicking the sensor device option. Figure 10c shows an example graph of the historical data of humidity. In order to enable the user to identify the anomaly of the cold chain environment in time, the software has designed the trigger module. In the trigger module, the user can set the environmental parameters threshold according to their needs. When the environmental data in the cold chain exceeds the threshold range, the software will issue warning information through the established display control, and the data font color will be displayed in red to notify the user in time.

Figure 11 shows the software interface of PC version. Through the software, the same as mobile version, user can get the real-time temperature humidity, temperature, oxygen, and carbon dioxide data of cold chain environment. Moreover, user also can query the historical data of the cold chain environment, as shown in Figure 12. 


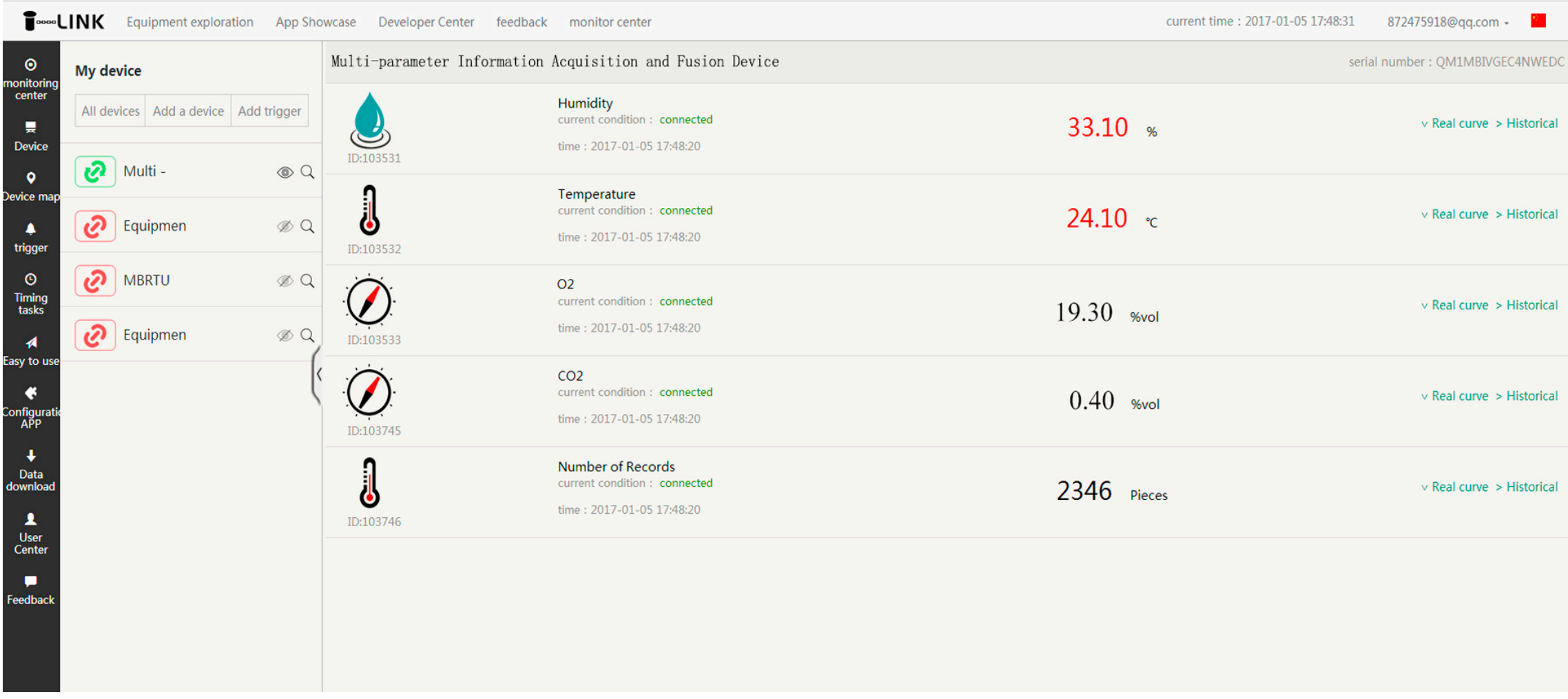

Figure 11. The PC version software interface. 


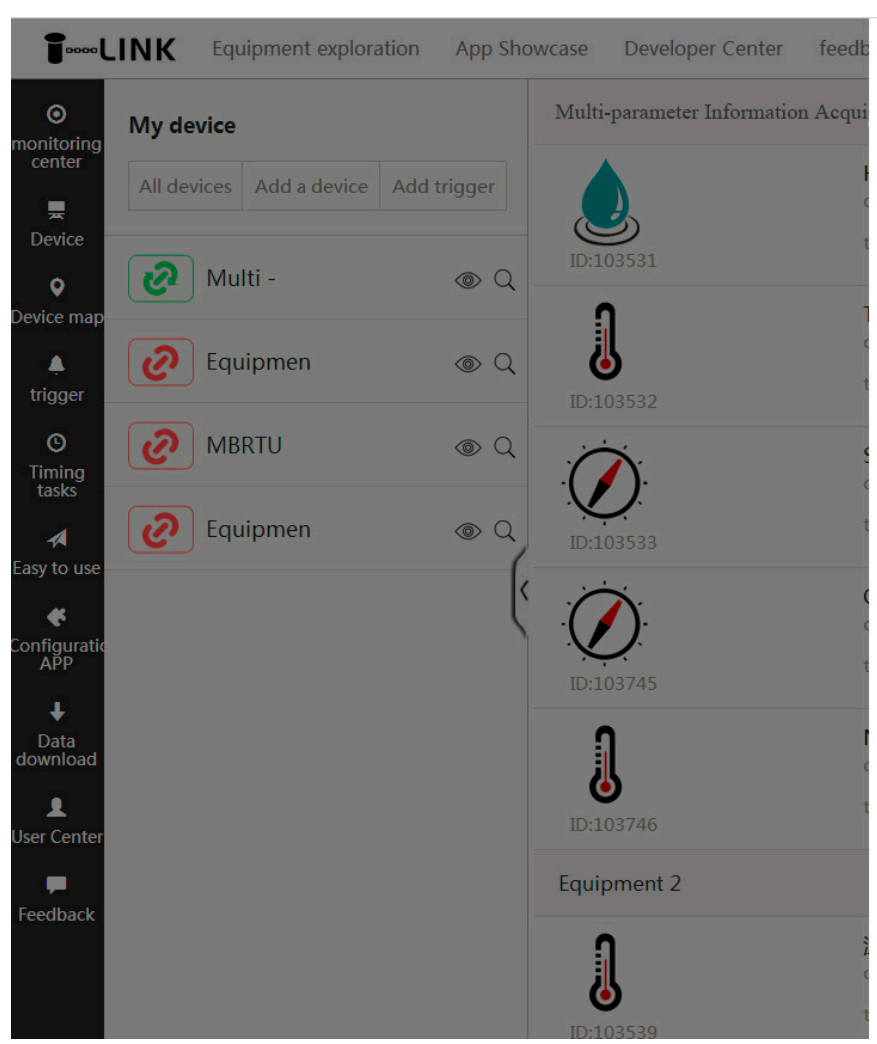

historical

Historical 1h 1d) Omonth 1month

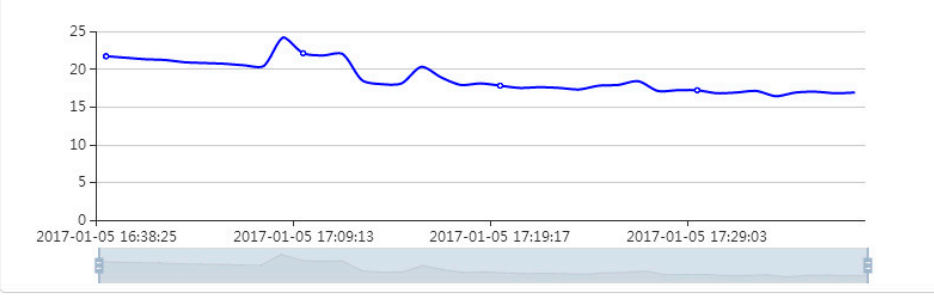

Sensorinformation

currentvalue : $17.30 \%$

evicename : Multi-parameter Information Acquisition and Fusion Device sensorname : Humidity

Types: Numeric

anrent condition : connected

Add trigger Edit

shut down

目 2017-01-05 - 2017-01-05

Q search

\begin{tabular}{|c|c|}
\hline data & time \\
\hline 17.30 & $2017-01-05$ 17:37:36.0 \\
\hline 16.90 & $2017-01-05$ 17:37:05.0 \\
\hline 17.20 & $2017-01-05$ 17:36:37.0 \\
\hline 16.80 & $2017-01-05$ 17:36:22.0 \\
\hline 16.90 & $2017-01-05$ 17:35:52.0 \\
\hline 16.90 & $2017-01-05$ 17:35:46.0 \\
\hline 17.00 & $2017-01-05$ 17:35:16.0 \\
\hline 16.70 & $2017-01-05$ 17:34:50.0 \\
\hline
\end{tabular}

Figure 12. Historical graph of humidity 


\subsection{RM-TM Communication Performance Test and Analysis}

Communication performance test and analysis are the crucial processes in the development of RM-TM. This communication performance test mainly detected the cumulative packet loss rate of the system during the transmission cycle, thereby detecting whether the remote wireless transmission performance of the system meets the requirements. Since the monitoring interval of the system is 1 min, the timeliness and accuracy of communication are required to be relatively high. In the test, the cold chain logistics vehicle carrying monitoring nodes traveled at a steady speed within a range of 50 $\mathrm{m}-60 \mathrm{~km}$ from the laboratory monitoring center, and transmitted a total of 80 sets of data. Each set of data includes temperature, humidity, and gas sensor data for a total of 30 bytes with a transmission interval of $60,000 \mathrm{~ms}$. Finally, the maximum packet loss rate of the system was measured to be $5.0 \%$. After analysis, it was found that when the cold chain logistics vehicle traveled to a distance of $50 \mathrm{~km}$, it entered the mountainous area, and the four sets of data caused by the poor GPRS signal were lost. With this in mind, the monitoring node device was designed with data storage functionality at design time. When the data monitored by the monitoring center is incomplete, the data stored by the monitoring node is used as supplementary data, and finally the data integrity can be achieved.

\subsection{System Evaluation of RM-TM}

The purpose of the system evaluation includes two aspects: on the one hand, it is evaluated whether the function of the RM-TM can meet the requirements of the end user, and on the other hand, whether the performance of the RM-TM is satisfactory and whether it can be further improved. The evaluation of RM-TM was finally completed by discussion by managers and experts from sampled enterprises and university. Table 5 presents Improvement suggestions for RM-TM. Table 6 shows the performance analysis of the RM-TM.

Table 5. Suggestions for RM-TM.

\begin{tabular}{lll}
\hline No. & Suggestion & Type \\
\hline 1 & Apply RM-TM in other production process in the enterprise & Functional \\
2 & Reduce the cost of RM-TM & Non-functional \\
3 & Reduce the size of the information acquisition hardware & Non-functional \\
4 & Increase the stability of RM-TM & Functional \\
\hline
\end{tabular}


Table 6. The performance analysis of the RM-TM.

\begin{tabular}{|c|c|c|c|c|c|c|c|}
\hline \multirow{2}{*}{ Performance Indicators } & \multirow{2}{*}{ Monitoring Situation } & \multirow{2}{*}{ Warning } & \multicolumn{4}{|c|}{ Transparency and Accuracy } & \multirow{2}{*}{ Applicability } \\
\hline & & & Temperature & Humidity & $\mathrm{CO}_{2}$ & $\mathrm{O}_{2}$ & \\
\hline Traditional work & None & Null & $\begin{array}{c}\text { Radio frequency } \\
\text { identification, recorders }\end{array}$ & $\begin{array}{c}\text { Radio frequency } \\
\text { identification, recorders }\end{array}$ & Null & Null & $\begin{array}{l}\text { Complexity, difficult, } \\
\text { time consuming }\end{array}$ \\
\hline Previous work in our team & Temperature \& humidity & Null & $\begin{array}{l}\text { Range: }-40 \text { to } 120^{\circ} \mathrm{C} \\
\text { Accuracy: } \pm 0.4{ }^{\circ} \mathrm{C}\end{array}$ & $\begin{array}{l}\text { Range:0-100\%RH } \\
\text { Accuracy: } \pm 3 \% R H\end{array}$ & Null & Null & Simple, easy \\
\hline Traceability system & $\begin{array}{l}\text { Temperature, humidity, } \\
\mathrm{CO}_{2} \text { and } \mathrm{O}_{2}\end{array}$ & Real-time & $\begin{array}{l}\text { Range: }-40 \text { to } 80^{\circ} \mathrm{C} \\
\text { Accuracy: } \pm 0.3^{\circ} \mathrm{C}\end{array}$ & $\begin{array}{l}\text { Range: } 0-100 \% \mathrm{RH} \\
\text { Accuracy: } \pm 2 \% \mathrm{RH}\end{array}$ & $\begin{array}{c}\text { Range: } 0-5 \% \\
\text { Accuracy: } \pm 2 \% \mathrm{FS} \\
\text { Response time }<25 \mathrm{~s}\end{array}$ & $\begin{array}{c}\text { Range: } 0-30 \% \\
\text { Accuracy: } \pm 1 \% \mathrm{FS} \\
\text { Response time }<25 \mathrm{~s}\end{array}$ & $\begin{array}{l}\text { Comprehensive, } \\
\text { real-time, easy, online } \\
\text { and simple }\end{array}$ \\
\hline Advantage & $\begin{array}{l}\text { The monitored } \\
\text { parameters were } \\
\text { increased }\end{array}$ & $\begin{array}{l}\text { Better management of } \\
\text { cold chain }\end{array}$ & $\begin{array}{l}\text { Better accuracy and } \\
\text { traceability }\end{array}$ & $\begin{array}{l}\text { Better accuracy and } \\
\text { traceability }\end{array}$ & $\begin{array}{c}\text { Capability of } \mathrm{CO}_{2} \\
\text { monitoring and } \\
\text { traceability }\end{array}$ & $\begin{array}{c}\text { Capability of } \mathrm{O}_{2} \\
\text { monitoring and } \\
\text { traceability }\end{array}$ & $\begin{array}{l}\text { Improving the } \\
\text { management of cold } \\
\text { chain }\end{array}$ \\
\hline
\end{tabular}




\section{Discussion and Conclusion}

This study analyzes the supply chain model of T. matsutake and describes the whole process of the cold chain of T. matsutake. According to actual requirements, this article presents a wireless monitoring and intelligent traceability system (RM-TM) using emerging IoT technologies. Finally, the system was evaluated and tested by tracking the T. matsutake cold chain logistics.

- RM-TM test and evaluation results show that RM-TM can effectively trace and monitor the real-time humidity, temperature, oxygen, and carbon dioxide fluctuations, which increase the traceability and transparency of the cold chain microenvironment.

- After the power consumption test, the multi-parameter information acquisition and fusion device can meet the power consumption requirements of T. matsutake cold chain logistics by extending the sleep time and reducing the acquisition frequency of the device.

- The implementation of the RM-TM can make the key parameters of the T. matsutake cold chain logistics micro-environment tracked in real-time, which provides data information and decision-making for managers. Further, the quality loss of the T. matsutake can be reduced, and the economic benefit is increased.

Based on the user's evaluation of the RM-TM and higher requirements, we also discussed the future work of RM-TM improvements and upgrades.

- The size of $\mathrm{CO}_{2}$ and $\mathrm{O}_{2}$ sensors used in the RM-TM are bulky, which makes it difficult to install the sensors in a small package of T. matsutake. Meanwhile, the price of the $\mathrm{CO}_{2}$ and $\mathrm{O}_{2}$ sensors are too expensive to be widely used. Therefore, the future work should integrate micro-gas sensor technology into RM-TM to reduce the size of the device and economic costs.

- The system has realized the real-time monitoring of the cold chain micro-environment of T. matsutake, but has not yet realized real-time monitoring of the quality of T. matsutake. Therefore, the future work should establish a gas-quality coupling model to achieve real-time monitoring of the quality of the T. matsutake.

This research makes important contributions to the wider applications of IoT in food supply chain operation and management. Besides, the approaches and processes developed for the system design and implementation of RM-TM can be adopted by other researchers and practitioners in cold chain management.

Author Contributions: Conceptualization: X.Z.; formal analysis: L.Y.; investigation: X.L.; methodology: X.Z.; project administration: Z.W.; writing—original draft: X.L.; writing—review and editing: Y.D.

Funding: This research was funded by National Nature Science Foundation of China for the project entitled "Mutilple information fusion based quality monitoring of Tibet edible fungi in cold chain", grant number 31460421.

Conflicts of Interest: The authors declare no conflict of interest. The funders had no role in the design of the study; in the collection, analyses, or interpretation of data; in the writing of the manuscript, or in the decision to publish the results.

\section{References}

1. Liu, H.; Zhang, J.; Li, T.; Shi, Y.; Wang, Y. Mineral element levels in wild edible mushrooms from Yunnan, China. Biol. Trace Elem. Res. 2012, 147, 341-345. [CrossRef] [PubMed]

2. Yun, W.; Hall, I.R.; Evans, L.A. Ectomycorrhizal fungi with edible fruiting bodies 1.Tricholoma Matsutake and Related Fungi. Econ. Bot. 1997, 51, 311-327. [CrossRef]

3. Bergius, N.; Danell, E. The Swedish matsutake (Tricholoma nauseosum syn. T. matsutake): Distribution, Abundance and Ecology. Scand. J. For. Res. 2000, 15, 318-325. [CrossRef]

4. Yang, X.; He, J.; Yang, Y.; Li, C.; Xu, J.; Ma, J. Matsutake Trade in Yunnan Province, China: An Overview. Econ. Bot. 2010, 62, 269-277. [CrossRef]

5. Jeng-Leun, M.; Hsiu-Ching, L.; Chin-Chu, C. Antioxidant Properties of Several Medicinal Mushrooms. J. Agric. Food Chem. 2002, 50, 6072-6077. 
6. Xue, Z.; Hao, J.; Yu, W.; Kou, X. Effects of Processing and Storage Preservation Technologies on Nutritional Quality and Biological Activities of Edible Fungi: A Review: Effects of processing and preservation technologies on edible fung. J. Food Process Eng. 2016, 40, e12437. [CrossRef]

7. Tsai, C.W.; Lai, C.F.; Vasilakos, A.V. Future Internet of Things: Open issues and challenges. Wirel. Netw. 2014, 20, 2201-2217. [CrossRef]

8. Akyildiz, I.F.; Pierobon, M.; Balasubramaniam, S.; Koucheryavy, Y. The internet of Bio-Nano things. IEEE Commun. Mag. 2015, 32-40. [CrossRef]

9. Augustin, A.; Yi, J.; Clausen, T.H.; Townsley, W. A Study of LoRa: Long Range \& Low Power Networks for the Internet of Things. Sensors 2016, 16, 1466.

10. Bello, O.; Zeadally, S. Intelligent Device-to-Device Communication in the Internet of Things. IEEE Syst. J. 2016, 10, 1172-1182. [CrossRef]

11. Farhan, L.; Shukur, S.T.; Alissa, A.; Alrweg, M.; Raza, U.; Kharel, R. A survey on the challenges and opportunities of the Internet of Things (IoT). In Proceedings of the 2017 Eleventh International Conference on Sensing Technology (ICST), Sydney, Australia, 4-6 December 2017; pp. 1-5.

12. Chandra, A.A.; Lee, S.R. A method of WSN and sensor cloud system to monitor cold chain logistics as part of the IoT technology. Int. J. Multimed. Ubiquitous Eng. 2014, 9, 145-152. [CrossRef]

13. Palattella, M.R.; Dohler, M.; Grieco, A.; Rizzo, G.; Torsner, J.; Engel, T.; Ladid, L. Internet of Things in the 5G Era: Enablers, Architecture, and Business Models. IEEE J. Sel. Areas Commun. 2016, 34, 510-527. [CrossRef]

14. Ruiz-Garcia, L.; Steinberger, G.; Rothmund, M. A model and prototype implementation for tracking and tracing agricultural batch products along the food chain. Food Control 2010, 21, 112-121. [CrossRef]

15. Coates, R.W.; Delwiche, M.J.; Broad, A.; Holler, M. Wireless sensor network with irrigation valve control. Comput. Electron. Agric. 2013, 96, 13-22. [CrossRef]

16. Aung, M.M.; Chang, Y.S. Temperature management for the quality assurance of a perishable food supply chain. Food Control 2014, 40, 198-207. [CrossRef]

17. Qi, L.; Xu, M.; Fu, Z.; Mira, T.; Zhang, X. C2SLDS: A WSN-based perishable food shelf-life prediction and LSFO strategy decision support system in cold chain logistics. Food Control 2014, 38, 19-29. [CrossRef]

18. Liu, C.; Zhang, R.; Chen, T.; Yi, T. The WSN Real-Time Monitoring System for Agricultural Products Cold-Chain Logistics. In Proceedings of the Computer and Computing Technologies in Agriculture VII; Li, D., Chen, Y., Eds.; Springer: Berlin/Heidelberg, Germany, 2014; pp. 255-261.

19. Saad, S.M.; Kamarudin, L.M.; Kamarudin, K.; Nooriman, W.M.; Mamduh, S.M.; Zakaria, A.; Shakaff, A.Y.M.; Jaafar, M.N. A real-time greenhouse monitoring system for mango with Wireless Sensor Network (WSN). In Proceedings of the 2014 2nd International Conference on Electronic Design (ICED), Penang, Malaysia, 19-21 August 2014; pp. 521-526.

20. Bhanarkar, M.; Korake, P. Soil salinity and moisture measurement system for grapes field by wireless sensor network. Cogent Eng. 2016, 3, 1164021. [CrossRef]

21. Bhargava, K.; Kashyap, A.; Gonsalves, T. Wireless sensor network based advisory system for Apple Scab prevention. In Proceedings of the 2014 Twentieth National Conference on Communications (NCC), Kanpur, India, 28 February-2 March 2014; pp. 1-6.

22. Xiao, X.; He, Q.; Fu, Z.; Xu, M.; Zhang, X. Applying CS and WSN methods for improving efficiency of frozen and chilled aquatic products monitoring system in cold chain logistics. Food Control 2016, 60, 656-666. [CrossRef]

23. Zhao, Z.; Li, Q.; Wu, X. SD Card-based Temperature Recorder for Blood Cold Chain. Instrum. Tech. Sens. 2008, 10, 25-27.

24. Alayev, Y.; Chen, F.; Hou, Y.; Johnson, M.P.; Bar-Noy, A.; La Porta, T.F.; Leung, K.K. Throughput maximization in mobile WSN scheduling with power control and rate selection. IEEE Trans. Wirel. Commun. 2014, 13, 4066-4079. [CrossRef]

25. Suryadevara, N.K.; Mukhopadhyay, S.C.; Kelly, S.D.T.; Gill, S.P.S. WSN-based smart sensors and actuator for power management in intelligent buildings. IEEE/ASME Trans. Mechatron. 2015, 20, 564-571. [CrossRef]

26. Li, C.M.; Nien, C.C.; Liao, J.L.; Tseng, Y.C. Development of wireless sensor module and network for temperature monitoring in cold chain logistics. In Proceedings of the 2012 IEEE International Conference on Wireless Information Technology and Systems (ICWITS), Maui, HI, USA, 11-16 November 2012; pp. 1-4. 
27. Gogou, E.; Katsaros, G.; Derens, E.; Alvarez, G.; Taoukis, P.S. Cold chain database development and application as a tool for the cold chain management and food quality evaluation. Int. J. Refrig. 2015, 52, 109-121. [CrossRef]

28. La Scalia, G.; Nasca, A.; Corona, O.; Settanni, L.; Micale, R. An Innovative Shelf Life Model Based on Smart Logistic Unit for an Efficient Management of the Perishable Food Supply Chain. J. Food Process Eng. 2017, 40. [CrossRef]

29. Sciortino, R.; Micale, R.; Enea, M.; La Scalia, G. A webGIS-based system for real time shelf life prediction. Comput. Electron. Agric. 2016, 127, 451-459. [CrossRef]

2019 by the authors. Licensee MDPI, Basel, Switzerland. This article is an open access article distributed under the terms and conditions of the Creative Commons Attribution (CC BY) license (http:/ / creativecommons.org/licenses/by/4.0/). 